\title{
The Effects of Memantine on Prepulse Inhibition
}

\author{
NR Swerdlow*,', DP van Bergeijk', F Bergsma', E Weber' and J Talledo' \\ 'Department of Psychiatry, University of Califormia, San Diego, La Jolla, CA, USA
}

Reduced prepulse inhibition (PPI) of startle provides evidence of deficient sensorimotor gating in several disorders, including schizophrenia. The role of NMDA neurotransmission in the regulation of PPI is unclear, due to cross-species differences in the effects of NMDA antagonists on PPI. Recent reports suggest that drug effects on PPI differ in subgroups of normal humans that differ in the levels of baseline PPI or specific personality domains; here, we tested the effects of these variables on the sensitivity of PPI to the NMDA antagonist, memantine. PPI was measured in male Sprague-Dawley rats, after treatment with memantine $(0,10$ or $20 \mathrm{mg} / \mathrm{kg}$, s.c.). Baseline PPI was then measured in 37 healthy adult men. Next, subjects were tested twice, in a double-blind crossover design, comparing either ( 1 ) placebo vs $20 \mathrm{mg}$ of the NMDA antagonist memantine $(n=19)$ or (2) placebo vs $30 \mathrm{mg}$ memantine $(n=18)$. Tests included measures of acoustic startle amplitude, PPI, autonomic indices and subjective self-rating scales. Memantine had dose- and intervaldependent effects on PPI in rats. Compared with vehicle, $10 \mathrm{mg} / \mathrm{kg}$ increased short-interval ( $10-20 \mathrm{~ms})$ PPI, and $20 \mathrm{mg} / \mathrm{kg}$ decreased long-interval (120 ms) PPI. In humans, memantine caused dose-dependent effects on psychological and somatic measures: $20 \mathrm{mg}$ was associated with increased ratings of happiness, and $30 \mathrm{mg}$ was associated with increased ratings of dizziness. PPI at the $120 \mathrm{~ms}$ prepulse interval was increased by $20 \mathrm{mg}$, but not $30 \mathrm{mg}$ of memantine. Subgroups most sensitive to the PPI-enhancing effects of memantine were those with low baseline PPI, or with personality scale scores suggestive of high novelty seeking, high sensation seeking, or high disinhibition. NMDA blockade with memantine appears to have dose- and interval-dependent effects on sensorimotor gating in rats and humans, particularly among specific subgroups of normal human subjects. These findings are discussed as they relate to consistencies across other studies in humans, as well as apparent inconsistencies in the NMDA regulation of PPI across species.

Neuropsychopharmacology (2009) 34, 1854-1864; doi:10.1038/npp.2009.7; published online 25 February 2009

Keywords: memantine; glutamate; prepulse inhibition; schizophrenia; sensorimotor gating; startle

\section{INTRODUCTION}

Startle can be reduced when the startling stimulus is preceded by a weak nonstartling prepulse (Ison and Hammond, 1971; Graham, 1975), in a process called prepulse inhibition (PPI). The degree to which the weak sensory prepulse inhibits the motor reflex in PPI is used as a measure of sensorimotor gating. PPI is disrupted in specific neuropsychiatric disorders, such as schizophrenia (Braff et al, 1978; cf. Braff et al, 2001), Tourette syndrome (Castellanos et al, 1996), obsessive compulsive disorder (Swerdlow et al, 1993; Hoenig et al, 2005), Huntington's disease (Swerdlow et al, 1995), and Fragile X syndrome (Frankland et al, 2004).

To clarify the pathophysiology of deficient sensorimotor gating in these disorders, one strategy has been to investigate the effects of pharmacological manipulations on PPI in normal human and animal models. For example,

*Correspondence: Dr NR Swerdlow, University of California, San Diego, Department of Psychiatry, 9500 Gilman Drive, La Jolla, CA 92093, USA, Tel: + 619543 6270, Fax: + 6195432493 ,

E-mail: nswerdlow@ucsd.edu

Received 30 September 2008; revised 19 November 2008; accepted 20 November 2008 many studies document the PPI-disruptive effects of dopamine (DA) agonists on PPI in rodents and normal humans (Mansbach et al, 1988; Hutchison and Swift, 1999; cf. Swerdlow et al, 2008). Even within this apparently consistent literature, there is clear evidence of cross-species differences. For example, the DAergic regulation of PPI may involve different DA receptor subtypes in rats $v s$ mice (Ralph and Caine, 2005). Furthermore, in normal humans, the effects of DAergic manipulations on PPI may differ across subgroups characterized by low $v s$ high baseline PPI levels (Swerdlow et al, 2003; Bitsios et al, 2005), and/or distinct personality dimensions (Hutchison et al, 1999; Swerdlow et al, 2006; Talledo et al, 2008).

Perhaps even more profound cross-species differences have been identified in the NMDA regulation of PPI. In rats, PPI is reduced by noncompetitive NMDA receptor antagonists, such as dizoclipine, ketamine and phencyclidine (Mansbach and Geyer, 1989; Mansbach and Geyer, 1991; Martinez et al, 1999, 2000). However, in healthy humans, ketamine has been shown to cause either an increase of PPI at short prepulse intervals (30 ms (Duncan et al, 2001; Abel et al, 2003), or have no significant effect on PPI (van Berckel et al, 1998). A similar PPI-enhancing effect was reported by Swerdlow et al (2002) in normal subjects who were 
administered the mixed NMDA antagonist/DA agonist, amantadine.

To better understand the role of NMDA neurotransmission in the normal regulation of PPI in humans, we tested the effects of the low-to-moderate affinity NMDA-receptor antagonist memantine on PPI. Memantine was chosen because it is well tolerated (compared with ketamine), has linear kinetics, $100 \%$ bioavailability after oral administration and relative NMDA-receptor selectivity (Wilcock et al, 2002; Areosa et al, 2005; Cummings, 2004). Memantine does not cause sensory or dissociative symptoms similar to those reported in past PPI studies with ketamine (Duncan et al, 2001; Abel et al, 2003), and which might potentially complicate the interpretation of changes in PPI. Wiley et al (2003) reported that in rats, memantine produced a dose-dependent reduction in PPI, using $100 \mathrm{~ms}$ prepulse intervals; initial studies here were designed to extend these studies of memantine in rats, across the range of prepulse intervals (10-120 ms) with which PPI was measured in humans. These studies next examined the effects of two doses of memantine (20 and $30 \mathrm{mg}$ ) on PPI in normal men. On the basis of several reports with DA agonists, this study also assessed the possible relationship between baseline PPI levels, normal personality dimensions, and sensitivity to the effects of memantine on PPI.

\section{MATERIALS AND METHODS}

The methods used in this study were approved by the UCSD Human Subject Institutional Review Board (human studies) or were in accordance with the National Institute of Health Guide for the Care and Use of Laboratory Animals (NIH publication no. 80-23) and approved by the UCSD Animal Subjects Committee (protocol no. S01221 (rodent studies)).

\section{Rodent Pilot Testing}

To confirm and extend findings of PPI-disruptive effects of memantine in rats (Wiley et al, 2003), adult male SD $(n=13)$ rats (225-250 g; Harlan Laboratories, San Diego, CA) were housed in groups of 2-3 animals per cage, and maintained on a reversed light/dark schedule with water and food available ad libitum. Rats were handled within 2 days of arrival. Testing occurred during the dark phase. Memantine $\mathrm{HCl}$ was dissolved in saline vehicle and administered s.c. in doses of 0,10 or $20 \mathrm{mg} / \mathrm{kg}$ (comparable to Wiley et al (2003)). Startle chambers (San Diego Instruments, San Diego, CA) were housed in a soundattenuated room, and consisted of a plexiglas cylinder $8.2 \mathrm{~cm}$ in diameter resting on a $12.5 \times 25.5-\mathrm{cm}$ plexiglas frame within a ventilated enclosure. Noise bursts were presented through a speaker mounted $24 \mathrm{~cm}$ above the cylinder. A piezoelectric accelerometer mounted below the plexiglas frame transduced motion within the cylinder. Stimulus delivery was controlled by the SR-LAB microcomputer and interface assembly, which also digitized (04095), rectified, and recorded stabilimeter readings. A total of 100 readings of $1 \mathrm{~ms}$ in duration were collected at the beginning of stimulus onset. Startle amplitude was defined as the average of the 100 readings.
Approximately 7 days after shipment arrival, rats were exposed to a short 'matching' startle session. They were placed in the startle chambers for a 5-min acclimation period with a $70 \mathrm{~dB}(\mathrm{~A})$ background noise, and then exposed to a total of $17 \mathrm{P}$-ALONE trails $(40 \mathrm{~ms}-120 \mathrm{~dB}(\mathrm{~A})$ noise bursts) that were interspersed with three $\mathrm{PP} 12 \mathrm{~dB}+\mathrm{P}$ ALONE trials (P-ALONE preceded $100 \mathrm{~ms}$ (onset-to-onset) by a $20 \mathrm{~ms}$ noise burst of $12 \mathrm{~dB}$ above background). Rats were assigned to dose groups based on average \%PPI from the matching session to ensure similar baseline PPI levels between groups. Four days later, rats were injected with memantine $(0,10$, or $20 \mathrm{mg} / \mathrm{kg})$, and $30 \mathrm{~min}$ later were placed in the startle chambers for a 5-min acclimation period with a $70-\mathrm{dB}(\mathrm{A})$ background noise. They were then exposed to a series of trial types, which were presented in pseudorandom order: (1) P-ALONE (40 ms, $120 \mathrm{~dB}(\mathrm{~A})$ noise burst); or P-ALONE preceded $10,20,30,60$, or $120 \mathrm{~ms}$ (onset-to-onset) by a 5 -ms noise $15 \mathrm{~dB}$ over background. Interspersed between these trials were trials in which no stimulus was presented, but cage displacement was measured (NOSTIM trials). The session began and ended with three consecutive P-ALONE trials; between these trials were six presentations of each trial type, in pseudorandom order. Intertrial intervals were variable and averaged $15 \mathrm{~s}$. NOSTIM trials were not included in the calculation of intertrial intervals. Total session duration was $15.5 \mathrm{~min}$.

\section{Human Participants}

A total of 40 healthy right-handed male healthy volunteers participated in the study. Female subjects were not included in the study because PPI is sexually dimorphic and fluctuates across the menstrual cycle. (Swerdlow et al, 1997; Jovanovic et al, 2004; Aasen et al, 2005). Exclusion criteria are outlined in Table 1.

Subjects who passed a preliminary phone checklist were invited for an in-person screening session that included a urine toxicology test (exclusion for any recreational drug), hearing test (Saico Audiometer, Assens Denmark; excluded for threshold $>40 \mathrm{~dB}(\mathrm{~A})$ at $1000 \mathrm{~Hz}$ ), and a startle reflex test (exclusion for mean startle magnitude $<50 \mathrm{U}$ ). During

Table I Exclusion Criteria

Exclusion criteria
I. Left-handedness
2. Female
3. Age: < I 8 and $>35$ years
3. Previous participation in a study involving PPI
4. Medical conditions, eg diabetes, HIV, cancer, hypertension, cerebrovascular
accident, and myocardial infarction
5. Self-reported loss of consciousness for more than I min
6. Current or past major mental illness as detected by SCID-NP
7. First degree relative with schizophrenia or major depression
8. Substance abuse or dependence
9. Current use of medication with potential memantine interactions or effects on
central nervous system
I0. Hearing impairment at 40 dB(A) at I000 Hz
I I. Mean eyeblink startle amplitude < 50 startle units


the screening, subjects also completed several questionnaires related to ethnicity, sexual preference, smoking, and caffeine consumption. Personality traits were quantified using the tridimensional personality questionnaire (TPQ; Cloninger et al, 1991) and the sensation seeking scale (SSS; Zuckerman et al, 1974).

For measures of acoustic startle and PPI, $\mathrm{Ag} / \mathrm{AgCl}$ electrodes (In vivo metric model E220X-LS) were positioned over and lateral to the orbicularis oculi underneath both eyes. A ground electrode was placed behind the left ear $(\mathrm{R}<10 \mathrm{k} \Omega)$. Eyeblink magnitude was measured using EMG recordings (San Diego Instruments, San Diego, CA). EMG activity was band-pass filtered $(1-1000 \mathrm{~Hz})$ and $60 \mathrm{~Hz}$ notch filtered, digitized, and 250 readings of $1 \mathrm{~ms}$ were recorded at the starting of the startle stimulus onset $(1.22 \mu \mathrm{V} / \mathrm{U})$. The startle test started with $3 \mathrm{~min}$ of $70 \mathrm{~dB}(\mathrm{~A})$ white noise, which persisted as a background noise during the test session. During acclimation, blinks were counted by trained observers using a radio shack security camera and monitor (interobserver $R=0.97$ ). The startle session consisted of 42 trials, with six conditions: a $118 \mathrm{~dB}(\mathrm{~A})$ white noise burst of $40 \mathrm{~ms}$ (pulse alone) and the same burst preceded 10, 20, 30, 60 , and $120 \mathrm{~ms}$ by a prepulse of $16 \mathrm{~dB}$ above the background. To measure startle habituation, three pulse alone trials were presented at the session beginning and end. The variable intertrial interval averaged $15 \mathrm{~s}$ (range $=10-20 \mathrm{~s}$ ). Total test time was $15 \mathrm{~min}$.

Participants who met study inclusion criteria returned for testing after 6-10 days, and for a second test one week later. Testing was performed double blind and drug order was randomized. Before the test days, subjects were instructed to maintain their normal patterns of caffeine intake before the testing, based on the effects of caffeine withdrawal on PPI and subjective rating scales. (Swerdlow et al, 2000). After arrival at $0830 \mathrm{~h}$ on the test day, subjects were given a standardized breakfast, followed by a urine toxicology test and a hearing test. At $0900 \mathrm{~h}$, either memantine hydrochloride $(20$ or $30 \mathrm{mg}$ ) or placebo was administered. For the first 20 subjects, the active dose of memantine hydrochloride was $20 \mathrm{mg}$. For the next 20 subjects, the active dose of memantine hydrochloride was $30 \mathrm{mg}$. Heart rate was measured manually and blood pressure was measured by brachial cuff. Symptom rating scales (SRS) were assessed 30, $90,150,200$, and 230 min after pill consumption. This SRS is a visual analog scale used to assess the physical and emotional states of the subjects during testing. Each symptom was rated on a piece of paper, using a $100-\mathrm{mm}$ line to separate extreme ratings ('not true' $v s$ 'true'). The subjects rated emotional state ('happy'), somatic symptoms ('queasy' and 'dizzy'), and consciousness ('drowsy'). The marks were manually measured by observers who were blind to the drug condition. At $1130 \mathrm{~h}$, the subjects received a standardized lunch. Startle testing began $210 \mathrm{~min}$ after pill administration, based on the reported pharmacokinetics of memantine in normal humans (Sonkusare et al, 2005), using a test session identical to that used the screening day. Additional psychophysiological measures were completed after this startle test, which will be analyzed separately.

The primary dependent measures for rodent and human studies were startle magnitude and PPI. PPI was defined as $(100-(100 \times$ magnitude on prepulse trial/magnitude on pulse alone trials)). Planned comparisons utilized drug and prepulse interval as within-subject factors, with separate analyses completed for the $20 \mathrm{mg}$ and $30 \mathrm{mg}$ doses of memantine in humans. Additional planned comparisons in humans analyzed the impact of baseline (screening) PPI levels and specific personality measures (novelty seeking (NS) based on the total NS score from the TPQ, and SSS, based on the total SSS score) on memantine PPI effects. These analyses utilized categorical factors ('low' $v s$ 'high' based on median splits) within ANOVAs, and continuous comparisons within regression analyses. Self-rating scales and autonomic measures at baseline (before pill administration) and immediately before startle testing were treated as continuous variables and analyzed by ANOVA as 'change scores' (difference from baseline); $\alpha$ was 0.05 . Additional exploratory analyses were conducted, with $\alpha$ corrected for multiple comparisons. When average startle magnitude was $<10 \mathrm{U}$ during testing, subjects were excluded as 'nonresponders'; this resulted in the exclusion of one subject in the $20 \mathrm{mg}$ memantine sample and two subjects in the $30 \mathrm{mg}$ memantine sample.

\section{RESULTS}

\section{Rodent Pilot Study}

Memantine caused a dose-dependent reduction in PPI for $60-120 \mathrm{~ms}$ prepulse intervals, confirming the findings of Wiley et al (2003). However, at short prepulse intervals $(10-20 \mathrm{~ms})$, the low dose of memantine increased PPI (Figure 1). ANOVA of \%PPI revealed a significant main effect of memantine $(\mathrm{F}=4.27$, d.f. $2,10, p<0.05)$ and prepulse interval $(\mathrm{F}=5.08$, d.f. $4,40, p<0.03)$, but no significant dose $\mathrm{x}$ interval interaction $(\mathrm{F}=1.32$, d.f. 8,40 , ns). Post hoc comparisons confirmed an overall reduction in PPI after $20 \mathrm{mg}$ memantine compared with vehicle $(p<0.035)$. One explicit goal of this exploratory study was

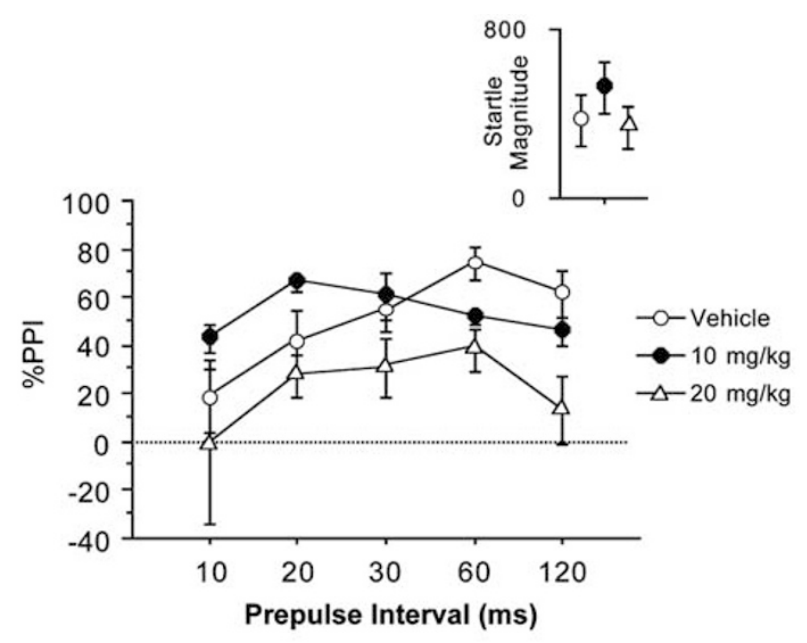

Figure I Pilot data to confirm and extend previous evidence of PPIdisruptive effects of memantine in rats (Wiley et al, 2003). Memantine produced a dose-dependent reduction in PPI with 60-120 ms intervals. However, at short intervals ( $10-20 \mathrm{~ms})$, PPI was both increased $(10 \mathrm{mg} / \mathrm{kg}$ ) and decreased $(20 \mathrm{mg} / \mathrm{kg})$ by memantine. Neither dose significantly altered startle magnitude (inset). 
Table 2 Final Sample Characteristics

\begin{tabular}{|c|c|c|}
\hline Final Cohort: & $\begin{array}{c}20 \mathrm{mg} \text { memantine } \\
(n=19)\end{array}$ & $\begin{array}{c}30 \text { mg memantine } \\
(n=18)\end{array}$ \\
\hline Age (years) mean (range) & $22.21(18-29)$ & $24.67(20-34)$ \\
\hline Weight (kg) (SEM) & $75.85(1.96)$ & $75.42(3.264)$ \\
\hline $\begin{array}{l}\text { Mean drug dose }(\mathrm{mg} / \mathrm{kg}) \\
\text { (SEM) }\end{array}$ & $0.267(0.007)$ & $0.409(0.016)$ \\
\hline $\begin{array}{l}\text { Caffeine Intake (mg/day) } \\
\text { (SEM) }\end{array}$ & I57.37 (37.59) & $86.35(22.57)$ \\
\hline Ethnicity $(\mathrm{C}-\mathrm{A}-\mathrm{H})^{\mathrm{a}}$ & $(||-3-5)$ & $(10-4-4)$ \\
\hline
\end{tabular}

${ }^{a}$ Caucasian: Asian: Hispanic.

Table 3 Personality Questionnaire Scores

\begin{tabular}{|c|c|c|}
\hline Final cohort & $\begin{array}{c}20 \mathrm{mg} \text { memantine } \\
(\text { mean }(\mathrm{SEM}) n=19)\end{array}$ & $\begin{array}{c}30 \mathrm{mg} \text { memantine } \\
(\text { mean }(\mathrm{SEM}) \mathrm{n}=18)\end{array}$ \\
\hline \multicolumn{3}{|l|}{$T P Q$} \\
\hline Novelty seeking (SEM) & $19.39(0.90)$ & $14.40(1.34)$ \\
\hline $\begin{array}{l}\text { Harm avoidance } \\
\text { (SEM) }\end{array}$ & $5.95(1.25)$ & $10.33(1.53)$ \\
\hline $\begin{array}{l}\text { Reward dependence } \\
\text { (SEM) }\end{array}$ & $21.05(0.69)$ & $19.72(1.36)$ \\
\hline \multicolumn{3}{|l|}{ SSS } \\
\hline SSS total score (SEM) & $23.63(0.96)$ & $20.95(1.75)$ \\
\hline $\begin{array}{l}\text { Thrill and adventure } \\
\text { seeking (SEM) }\end{array}$ & $8.32(0.51)$ & $7.67(0.63)$ \\
\hline $\begin{array}{l}\text { Experience seeking } \\
\text { (SEM) }\end{array}$ & $6.26(0.4 I)$ & $5.33(50.5 \mathrm{I})$ \\
\hline Disinhibition (SEM) & $5.53(0.54)$ & $4.56(0.64)$ \\
\hline $\begin{array}{l}\text { Boredom susceptibility } \\
\text { (SEM) }\end{array}$ & $3.53(0.42)$ & $3.11(0.48)$ \\
\hline
\end{tabular}

to examine memantine effects across the range of prepulse intervals, and a separate comparison of vehicle $v s 10 \mathrm{mg}$ memantine confirmed a dose $\times$ interval interaction $(\mathrm{F}=3.66$, d.f. $4,28, p<0.02)$, reflecting memantine-induced increases in PPI over the $10-20 \mathrm{~ms}$ intervals, with the opposite effect at longer intervals (Figure 1). There were no effects of memantine on startle magnitude ( $\mathrm{F}<1$; Figure 1 , inset) or reflex habituation (not shown).

\section{Human Study}

Subject characteristics. Human subject characteristics for the final cohorts in the 20 and $30 \mathrm{mg}$ studies are shown in Table 2. There were no differences in age, weight, ethnicity, or caffeine consumption $(p>0.10)$ across dose groups; one subject in the $20 \mathrm{mg}$ study and two subjects in the $30 \mathrm{mg}$ study were smokers.

Personality questionnaire scores are shown in Table 3. ANOVA for analyses personality questionnaire scores showed no difference between samples tested with $20 \mathrm{vs}$ $30 \mathrm{mg}$ memantine, with the exception of the TPQ subscale 'harm avoidance'. The values for this personality subscale were significantly higher for $30 \mathrm{mg}$ than for $20 \mathrm{mg}$ cohorts $(\mathrm{F}=7.65, p<0.015)$. Score ranges were consistent with those published in large scale studies from other groups (Earleywine et al, 1992; Eisenberg et al, 2007) and from our own group (Swerdlow et al, 2002).

Subjective and physiological measures. An increase in selfreported level of happiness at the time of startle testing was detected after administration of $20 \mathrm{mg}$ memantine $(\mathrm{F}=4.80$, d.f. $1,18, p<0.042)$, but not after the $30 \mathrm{mg}$ dose $(\mathrm{F}<1)$. This effect at $20 \mathrm{mg}$ reflected a part of the sustained increase in 'happy' ratings, from the initial evaluation $(30 \mathrm{~min}$ after pill), extending to the evaluation that followed the startle test $(\mathrm{F}=5.10$, d.f. $1,18, p<0.04$ for $30-230 \mathrm{~min}$ after pill; Figure $2 \mathrm{a})$. Increased dizziness ratings were evident at the time of startle testing with $30 \mathrm{mg}$ memantine $(\mathrm{F}=7.27$, d.f. $1,17, p<0.016)$, but not with the $20 \mathrm{mg}$ dose $(\mathrm{F}=2.58$, d.f. $1,18, \mathrm{~ns})$. This effect at $30 \mathrm{mg}$ reflected a part of the sustained increase in 'dizzy' ratings, extending from the third assessment (150 min after pill) to the evaluation after startle testing $(\mathrm{F}=9.23$, d.f. $1,17, p<0.008$ for $30-230 \mathrm{~min}$ after pill; Figure 2b). No significant changes in self-rated queasiness or drowsiness were detected at the time of startle testing with either dose of memantine (not shown). In general, subjective ratings of memantine effects ('happy' or 'dizzy') during the time of startle testing were not related to personality measures (data not shown).

Autonomic measures were not significantly changed by either dose of memantine. ANOVAs of heart rate, systolic, and diastolic blood pressure immediately before startle testing revealed no significant effects of either $20 \mathrm{mg}$ memantine $(\mathrm{F}=1.25,<1$ and 1.07 , respectively; $\mathrm{ns})$ or $30 \mathrm{mg}$ memantine ( $\mathrm{F}=3.43,<1$ and 1.72, respectively; $\mathrm{ns})$. Spontaneous blink rate immediately before startle testing was significantly reduced after $20 \mathrm{mg}$ memantine $(\mathrm{F}=4.75$, d.f. $1,18, p<0.045)$, but only a weak trend towards reduced blink rate was detected after $30 \mathrm{mg}$ memantine $(\mathrm{F}=1.41$, d.f. 1.17 , ns).

Startle magnitude and habituation. ANOVAs revealed no significant effect of 20 or $30 \mathrm{mg}$ memantine on startle magnitude ( $\mathrm{F}<1$, both comparisons). In each case, startle magnitude was greater for right eye than left $(\mathrm{F}=9.26$, d.f. $1,18 p<0.008$ and $\mathrm{F}=19.96$, d.f. $1,17, p<0.0004$ for 20 and $30 \mathrm{mg}$ doses, respectively), but there were no significant interactions of dose $\times$ eye side ( $\mathrm{F}<1$ and 1.37, respectively). Similarly, ANOVAs revealed no significant drug effects on reflex habituation, with significant effects of trial block for 20 and $30 \mathrm{mg}$ memantine tests $(\mathrm{F}=41.91$ and 36.28 , respectively), but no significant main effects of drug dose $(\mathrm{F}<1$ and 1.20 , respectively) or significant dose $\times$ block interaction $(\mathrm{F}<1)$.

PPI. ANOVAs of PPI yielded different outcomes for the 20 and $30 \mathrm{mg}$ doses of memantine (Figure $4 \mathrm{a}$ ). For the $20 \mathrm{mg}$ dose, ANOVA revealed no significant main effect of dose $(\mathrm{F}<1)$, a significant main effect of prepulse interval $(\mathrm{F}=33.62$, d.f. $4,72, p<0.0001)$, and a significant interaction of dose $\mathrm{x}$ interval $(\mathrm{F}=2.70$, d.f. $4,72, p<0.038)$. Post hoc comparisons revealed significant memantine-induced increases in PPI at $120 \mathrm{~ms}$ prepulse intervals $(p<0.025)$. A memantine-induced reduction in PPI at $10 \mathrm{~ms}$ intervals was 

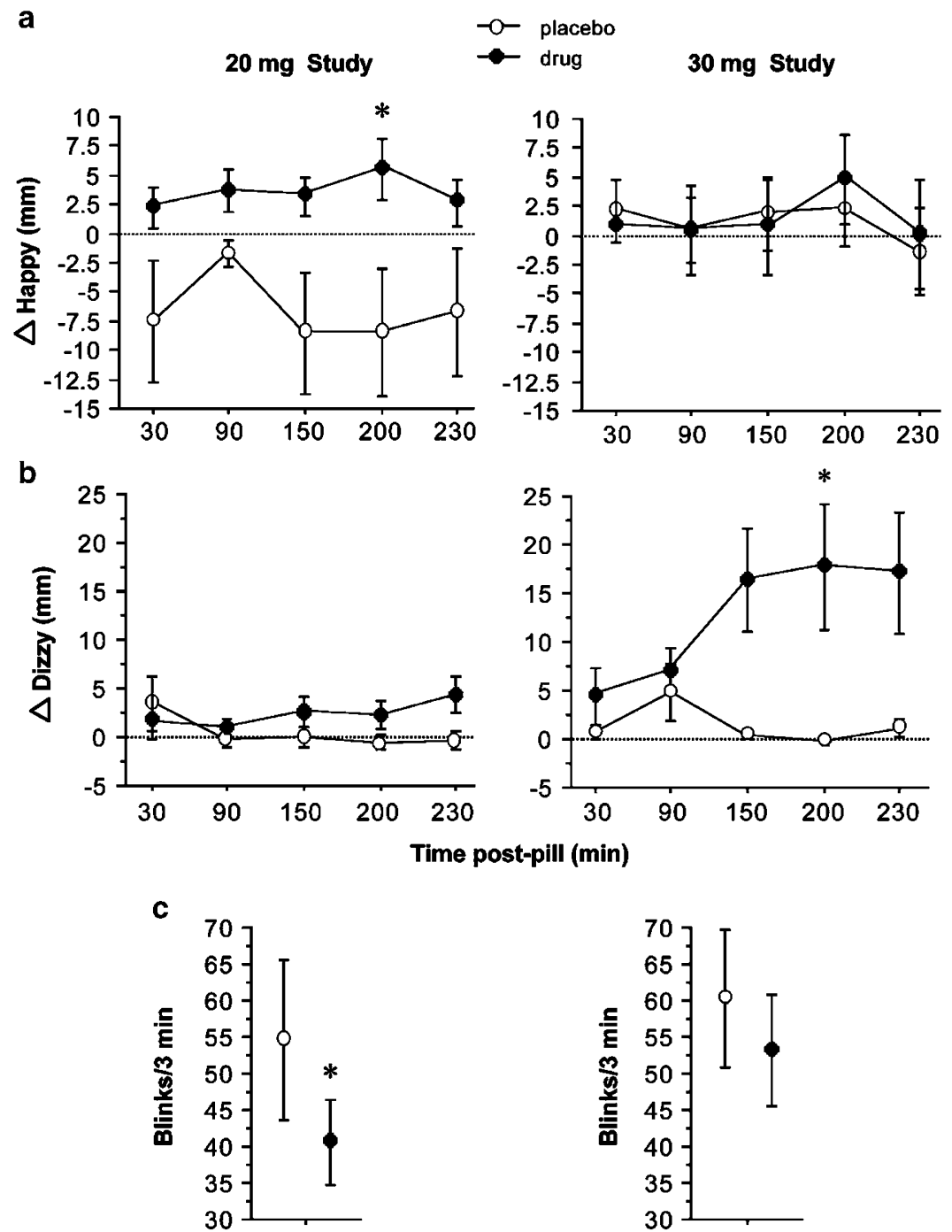

Figure 2 Evidence of bioactivity of $20 \mathrm{mg}$ (left figures) and $30 \mathrm{mg}$ (right figures) memantine. The $20 \mathrm{mg}$ dose increased ratings of 'happy' (a) and reduced spontaneous blink rates (c); the $30 \mathrm{mg}$ dose increased ratings of 'dizzy' (b). Each of these effects was statistically reliable immediately before startle testing (*).

not statistically significant $(\mathrm{F}=1.61)$, and achieved only a moderate effect size $(\mathrm{d}=0.42)$. For the $30 \mathrm{mg}$ dose of memantine, ANOVA revealed no significant main effect of dose $(\mathrm{F}<1)$, a significant effect of prepulse interval $(\mathrm{F}=21.07$, d.f. 4,68, $p<0.0001)$, and no significant dose $\times$ interval interaction $(\mathrm{F}<1)$. For both 20 and $30 \mathrm{mg}$ doses, ANOVAs of PPI noted no significant effects of eye side $(\mathrm{F}<1)$ or significant interactions of eye side with dose or interval; as a result, eye side was not entered as a factor in subsequent ANOVAs.

As planned, we next assessed the relationship between baseline PPI and memantine-induced changes in PPI, based on earlier reports of differential drug effects on PPI in lowvs high-gating individuals (Swerdlow et al, 2002, 2006; Bitsios et al, 2005; Csomor et al, 2008). Because different studies have used slightly different definitions of 'baseline PPI', we examined this relationship in a number of ways. For example, Bitsios et al (2005) distinguished 'low- vs highgating' subgroups based on mean screening PPI for $80 \mathrm{~ms}$ prepulse intervals. Because no $80 \mathrm{~ms}$ interval condition was included in this study, we used a similar approach, based on the averaged screening values for 60 and $120 \mathrm{~ms}$ prepulse intervals. Csomor et al (2008) stratified subjects based on vehicle-PPI levels for $60 \mathrm{~ms}$ prepulse intervals, and we (Swerdlow et al, 2002) had previously stratified subjects based on mean screening PPI values across $10-120 \mathrm{~ms}$ prepulse intervals. Importantly, all of these strategies yielded comparable outcomes with the present data; for simplicity, we will report the statistical outcomes only for analyses using the methods of Bitsios et al (2005).

For tests with $20 \mathrm{mg}$ memantine (Figure 4b), ANOVA of PPI revealed significantly higher PPI levels in 'high $v s$ 'low gaters' (reflecting the fact that screening PPI levels (4A, left) significantly predict testing PPI levels; $F=8.70$, d.f. 1,17 , $p<0.01)$, no overall main effect of drug dose $(\mathrm{F}<1)$, a significant interaction of drug $\times$ 'gating level' $(\mathrm{F}=4.96$, d.f. $1,17, p<0.04)$, a significant main effect of prepulse interval $(\mathrm{F}=44.12$, d.f. $4,68, p<0.0001)$, and significant interactions of dose $\times$ interval $(\mathrm{F}=2.75$, d.f. $4,68, p<0.04)$ and 'gating level' $\times$ interval $(\mathrm{F}=5.88$, d.f. $4,68, p<0.0005)$. On the basis of the interaction of drug $\times$ gating levels, separate ANOVAs were conducted in each gating subgroup that revealed a 
a

$20 \mathrm{mg}$ study

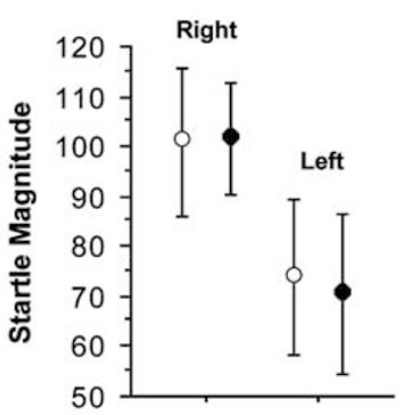

$30 \mathrm{mg}$ study

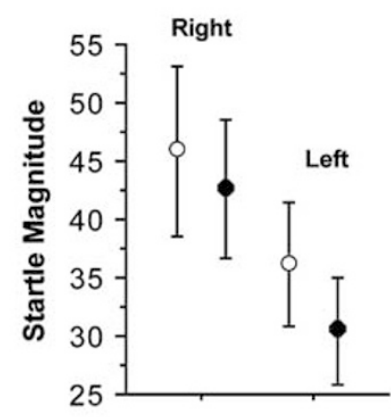

O placebo

- drug

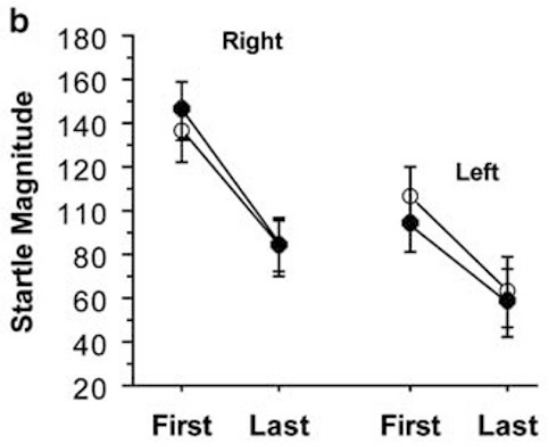

Trial Block

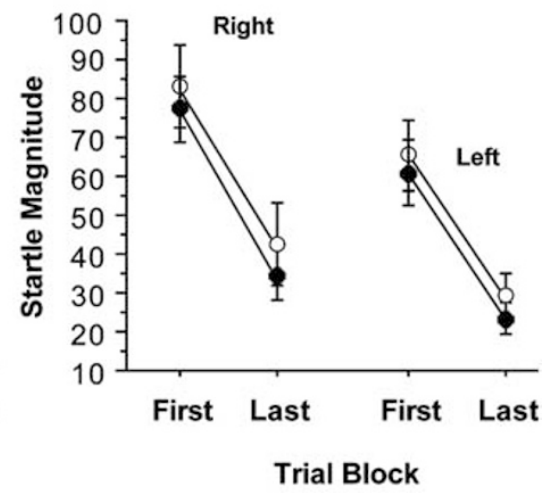

Figure 3 Startle magnitude on pulse alone trials during PPI testing (a), and at the beginning and end of each test session (b) were not significantly affected by either dose of memantine. Similarly, reflex habituation (response decrement from session beginning to end) was not affected by memantine (b).

significant interaction of drug $\times$ prepulse interval in 'high gaters' $(\mathrm{F}=2.66$, d.f. $4,36, p<0.05)$, but not 'low gaters' $(\mathrm{F}=1.14$, d.f. 4,32 , ns). Inspection of the data (Figure $4 \mathrm{~b}$ ) revealed that memantine increased PPI in the 'low-gating' group across all intervals, but particularly at the $120 \mathrm{~ms}$ prepulse interval $(\mathrm{F}=11.44$, d.f. $1,9, p<0.009)$, and that it tended to reduce PPI in the 'high-gating' group at the 10$20 \mathrm{~ms}$ prepulse intervals $(\mathrm{d}=0.75-0.77)$.

For tests with $30 \mathrm{mg}$ memantine (Figure 4c), ANOVA of PPI confirmed higher PPI levels in 'high gaters' $(\mathrm{F}=5.32$, d.f. $1,16, p<0.035)$, no overall main effect of drug $(\mathrm{F}<1)$ or interaction of drug $\times$ 'gating level' $(\mathrm{F}<1)$, a significant effect of prepulse interval $(\mathrm{F}=23.42$, d.f. $4,64, p<0.0001)$, and a significant interaction of gating level $\times$ interval $(\mathrm{F}=2.91$, d.f. 4,64, $p<0.03)$, but not gating level $\times$ interval $\times$ drug $(\mathrm{F}<1)$. Inspection of the data confirmed no differential impact of $30 \mathrm{mg}$ memantine on low- $v s$ highgating normal subject groups.

Personality and memantine effects on PPI. As planned, on the basis of the evidence for greater drug effects on PPI associated with specific personality dimensions, we assessed the relationship between memantine effects on PPI and scores for NS (NS total score from the TPQ), sensation seeking (SSS total score), and disinhibition (DIS subscale from the SSS scale; Figure 5a and b). Importantly, these scores were interrelated: NS scores correlated significantly with SSS scores $(R=0.64, p<0.004)$, but not DIS scores $(R=0.17, \mathrm{~ns})$, and total SSS scores correlated significantly with scores on its DIS subscale $(R=0.49, p<0.035$; in contrast, HA scores did not correlate significantly with any of these scales). Subgroups were formed based on median splits of NS and SSS scales, and the DIS subscale. We first examined the effect described above for the inclusive group of subjects tested with $20 \mathrm{mg}$ memantine: a drug-induced increase in PPI at the $120 \mathrm{~ms}$ prepulse interval. Separate ANOVAs showed that this effect was evident in subgroups with the highest scores in NS $(\mathrm{F}=5.54$, d.f. $1,8, \quad p<0.05)$, SSS $(\mathrm{F}=13.50$, d.f. 1,9 , $p<0.006)$ and DIS $(\mathrm{F}=7.75$, d.f. $1,8, p<0.025)$, but not in subgroups with the lowest scores in these domains $(\mathrm{F}=1.40,<1$, and $<1$, respectively). Looking beyond the $120 \mathrm{~ms}$ interval, DIS scores significantly predicted the overall impact of $20 \mathrm{mg}$ memantine on PPI; ANOVA revealed a significant interaction of dose $\times$ DIS group $(\mathrm{F}=12.31$, d.f. $1,17, p<0.003)$; a separate ANOVA in the high DIS subgroup revealed PPI-enhancing effects of memantine at all prepulse intervals (main effect of dose, $\mathrm{F}=6.90$, d.f. $1,8, p<0.035$ ), whereas a separate ANOVA in the low DIS group revealed significant PPI-reducing effects of memantine $(\mathrm{F}=5.38$, d.f. $1,9, p<0.05)$ that were most prominent at the short prepulse intervals (dose $\times$ interval interaction: $\mathrm{F}=3.28$, d.f. $4,36, p<0.025$ ). As a result, DIS scores correlated significantly with the impact of memantine on PPI (calculated by the difference score (memantine-placebo) for mean \%PPI across all intervals; $R=0.63$, $p<0.009$ ). Importantly, only the effects of memantine on PPI, and not baseline PPI levels per se, or post-placebo 
a

-0 placebo

20 mg Study

- drug

30 mg Study
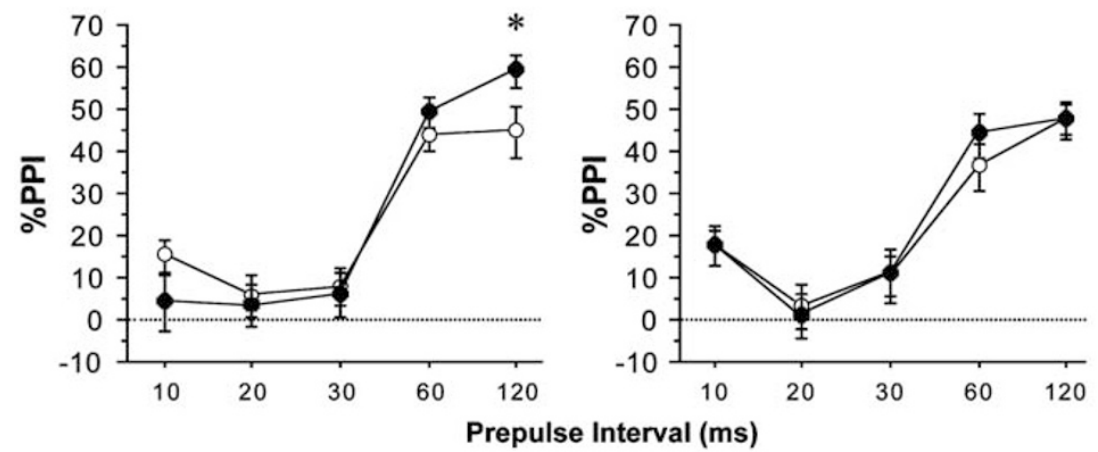

b $20 \mathrm{mg}$ Study
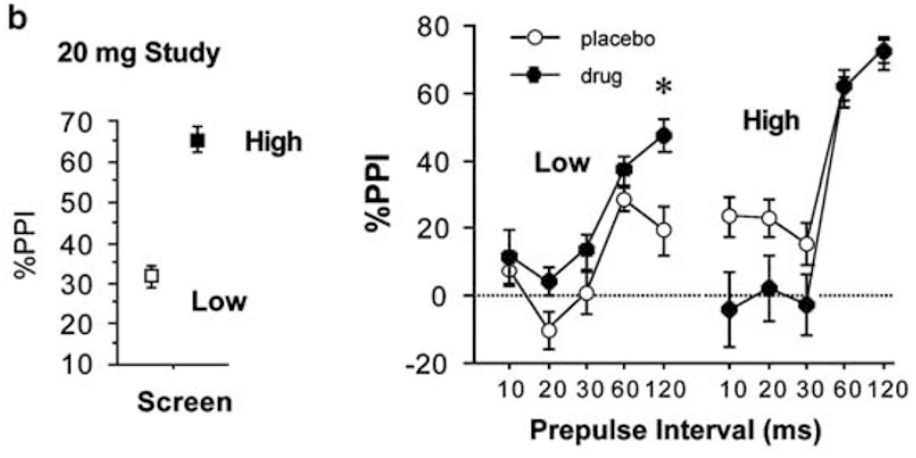

C
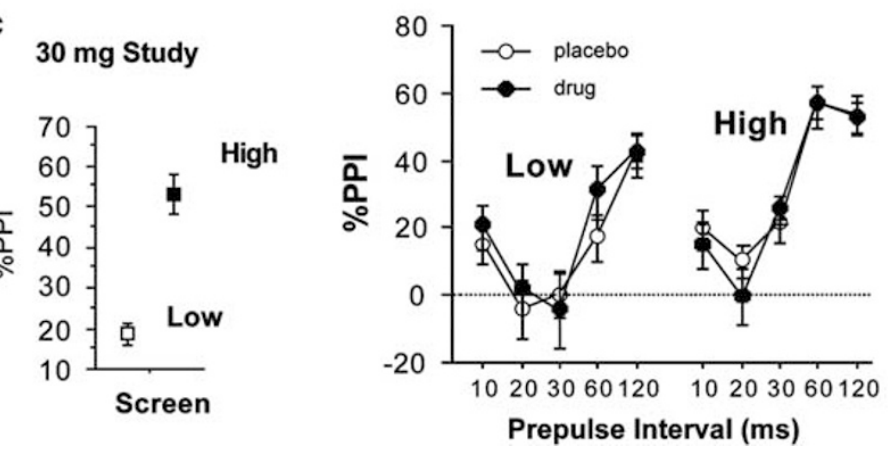

Figure 4 Effects of memantine on PPI. (a) PPI was significantly increased by $20 \mathrm{mg}$ memantine at 120 ms prepulse intervals (left), but was not significantly affected by $30 \mathrm{mg}$ memantine (right). (b) When subjects in the $20 \mathrm{mg}$ study were divided into those in the upper or lower 50\% of screening PPI values (left figure, 'high' and 'low', respectively), ANOVA revealed PPI-enhancing effects of memantine only among the 'low gaters'. PPI-reducing effects of memantine in 'high gaters' at short intervals did not reach statistical significance. (c) A similar 'low vs high gater' split uncovered no significant effects of 30 mg memantine on PPI.

or -memantine levels of startle magnitude, differed among subgroups with low vs high NS, SSS, or DIS scores.

Similar analyses using data from the $30 \mathrm{mg}$ memantine trial revealed no significant differences in memantine effects among subgroups with low vs high scores on NS, SSS, or DIS scales.

\section{DISCUSSION}

The main aim of this study was to assess the effects memantine on PPI, psychological, and somatic measures in clinically normal men. Initial pilot data obtained in rodents confirmed earlier reports of memantine's PPI-disruptive effects at longer prepulse intervals (Wiley et al (2003)), but also detected PPI-enhancing properties of memantine at short prepulse intervals, at a moderate dose of memantine, ie one that caused a submaximal disruption at long intervals. Thus, even with a cursory assessment, animal data suggested both dose- and interval-dependent effects of memantine on PPI, generally consistent with those previously observed with ketamine (Mansbach and Geyer, 1989).

In humans, we detected evidence for bioactivity of both doses of memantine at the time of startle testing: $20 \mathrm{mg}$ increased ratings of happiness and reduced spontaneous blink rate, whereas $30 \mathrm{mg}$ increased the ratings of dizziness. Interestingly, these drug effects did not overlap across doses: $30 \mathrm{mg}$ memantine did not change 'happiness' ratings, and although $20 \mathrm{mg}$ memantine may have generated some 

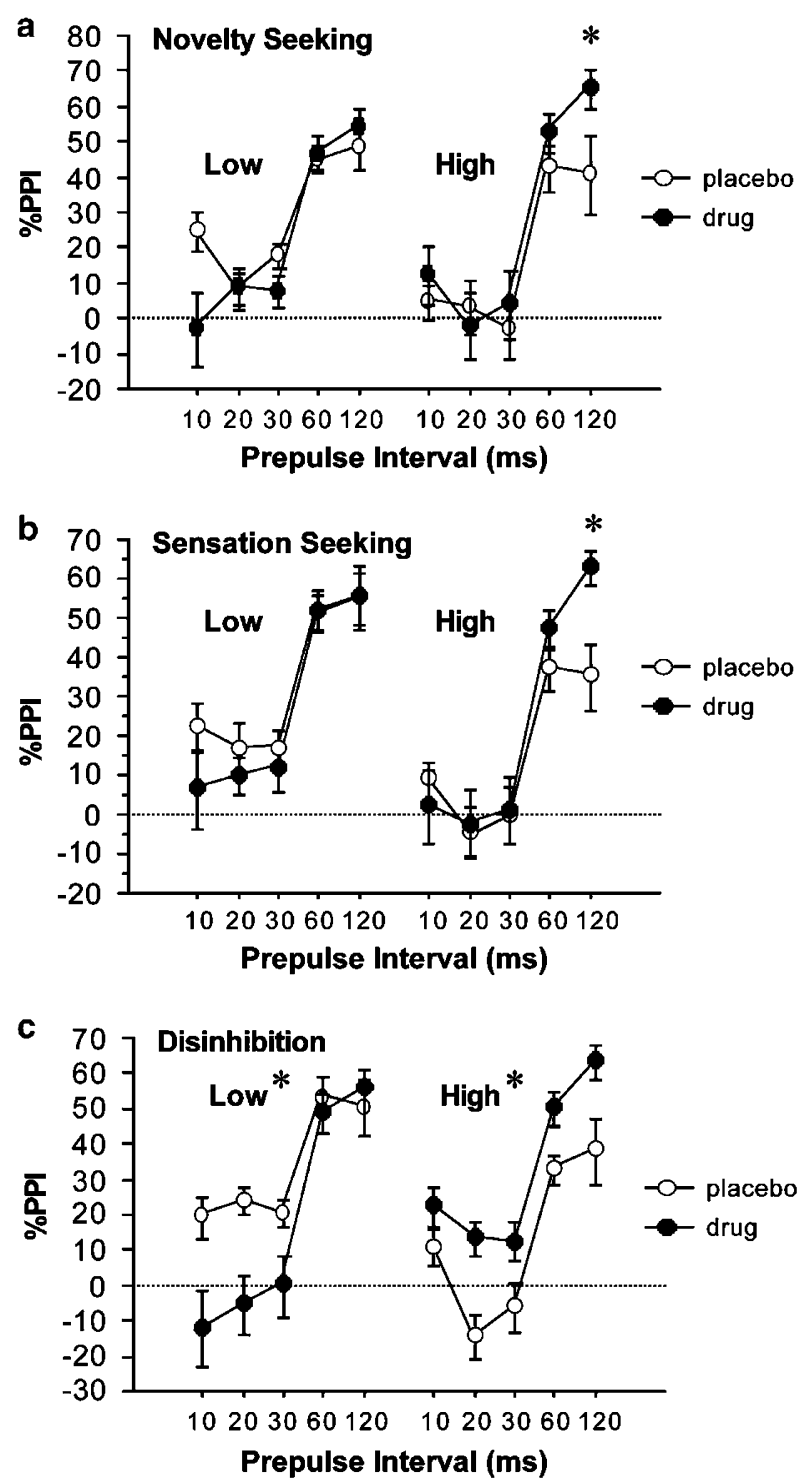

Figure 5 Differential effects of memantine on PPI among subjects with low vs high scores in personality measures of novelty seeking (a), sensation seeking (b), and disinhibition (c). PPI-enhancing effects of memantine at 120 ms prepulse intervals were evident only among individuals with high NS (a) or SSS scores (b). Subjects with high DIS scores exhibited PPIenhancing effects of memantine across all prepulse intervals, whereas subjects with low DIS scores exhibited the opposite effects, particularly at short prepulse intervals.

mild dizziness (Figure $2 \mathrm{~b}$ ) and $30 \mathrm{mg}$ memantine may have slightly slowed spontaneous blinking (Figure 2c), neither of these effects approached statistical significance. In fact, beyond changes in happiness and blink rate $(20 \mathrm{mg})$ and dizziness $(30 \mathrm{mg})$, there were no significant drug effects on drowsiness, queasiness, autonomic measures, startle magnitude, or startle habituation.

These findings (and lack thereof) with subjective measures are in line with the effects of memantine reported in the literature. These drug effects on happiness, blink rate (20 $\mathrm{mg}$ memantine), and dizziness ( $30 \mathrm{mg}$ memantine) were detected at a time point corresponding to peak memantine blood levels (Sonkusare et al, 2005). Euphoric effects were reported after $40 \mathrm{mg}$ memantine in adults with a history of methamphetamine abuse, and in patients with Alzheimer's disease (Hart et al, 2002; cf. Areosa et al, 2005). Dizziness is one of the most common side effects of memantine in clinical trials (Wilcock et al, 2002, cf. Kumar, 2004). Changes in blink rate are often viewed as a marker of central DAergic tone (Karson, 1983); in our experience, however, this association can be complicated by levels of drowsiness (that can increase blink rates) or alertness (that can decrease blink rates).

Generally, consistent with earlier reports with NMDA antagonists, such as ketamine (Duncan et al, 2001; Abel et al, 2003) and amantadine (Swerdlow et al, 2002 (but see Bitsios et al, 2005)), $20 \mathrm{mg}$ memantine significantly increased PPI at the $120 \mathrm{~ms}$ prepulse interval. In earlier reports, ketamine effects on PPI were either short lived (Duncan et al, 2001), or accompanied by reduced startle magnitude (Abel et al, 2003). Abel et al (2003) detected these PPI-enhancing effects of ketamine at both 30 and $120 \mathrm{~ms}$ prepulse intervals. Notably, the temporal pattern of memantine effects on PPI in humans contrasts sharply with that detected in rats: where humans exhibit maximal PPI enhancement (120 ms intervals), rats exhibit maximal PPI disruption; where rats exhibit maximal PPI enhancement (10-20 ms intervals), humans exhibit a trend towards PPI disruption.

On the basis of recent reports of differential drug effects on PPI between individuals with low $v s$ high baseline PPI levels, we conducted separate analyses of $20 \mathrm{mg}$ memantine effects on PPI in low vs high 'gating' subgroups. Memantine-induced increases in PPI were evident only in subjects ranked in the lowest $50 \%$ for baseline PPI; in this group, PPI-enhancing effects were apparent across the $10-120 \mathrm{~ms}$ range of prepulse intervals, but remained most robust at the $120 \mathrm{~ms}$ interval. In contrast, among 'high-gating' subjects, no PPI-enhancing effects of memantine were detected, and the opposite trend-decreased PPI-was apparent at short prepulse intervals.

These patterns of PPI-enhancement only in 'low-gating' subjects cannot be easily ascribed to a simple 'regression to the mean' of PPI levels. PPI (particularly at $60-120 \mathrm{~ms}$ intervals) has very high test-retest reliability, exceeding 0.80 over periods as long as 1 year (Cadenhead et al, 1999; Light et al, 2007). This makes it very unlikely that PPI levels would systematically fluctuate between 'low' and 'high' PPI levels across tests. More evidence that PPI-enhancing effects of memantine do not simply reflect an arithmetic consequence of low baseline PPI was seen when subgroups were formed based on specific personality domains. These subgroups did not differ significantly in baseline PPI, and yet PPI-enhancing effects of memantine at $120 \mathrm{~ms}$ prepulse intervals were detected only in subjects with the highest NS, SSS or DIS scores.

Low $v s$ high gating and low $v s$ high DIS subgroups differ not only in the 'direction' of memantine effects on PPI, but also in the prepulse intervals most sensitive to these effects. For example, although high DIS subjects exhibited PPIenhancing effects of memantine across all prepulse intervals, low DIS subjects exhibited significant PPI-reducing effects of memantine only at the short prepulse intervals; a similar pattern characterized low- $v$ s high-gating subgroups, respectively. In preclinical studies, short and long PPI intervals have been shown to be differentially sensitive to 
drug effects; indeed, this was the case in the present pilot study: short-interval PPI was increased by $10 \mathrm{mg} / \mathrm{kg}$ memantine, whereas at long PPI intervals, memantine produced only dose-dependent PPI-reducing effects. Some findings suggest differential neurochemical substrates regulating drug effects on short- and long-interval PPI, eg a prominent role of D1-like systems in regulating shortinterval PPI, and D2-like systems in regulating long-interval PPI (Swerdlow et al, 2004). At a psychological level, shortinterval PPI is linked to substrates regulating more automatic, preconscious inhibition, whereas long-interval PPI is linked to more volitional, consciously controlled inhibition (cf. Swerdlow et al, 2008). Conceivably, individuals distinguished by low vs high DIS scores, or high $v s$ low baseline PPI, might be differentially sensitive to shortvs long-interval PPI effects based on intrinsic differences in both these neurochemical and/or psychological substrates.

Perhaps most striking is the fact that no significant changes in PPI were evident after $30 \mathrm{mg}$ memantine, regardless of baseline PPI levels, or scores on NS, SSS, or DIS scales. Two parsimonious explanations for differences in memantine dose effects are (1) different sample characteristics and (2) a narrow range of dose sensitivity. Cohorts tested with 20 and $30 \mathrm{mg}$ doses were recruited from the same populations, using identical inclusion/exclusion criteria, and did not differ significantly in age, ethnicity, education level, weight, caffeine use, scores for NS, SSS and DIS scales, and baseline PPI levels ( $p>0.05$, both across all intervals, and for the critical mean of 60 and $120 \mathrm{~ms}$ intervals used for median split analyses). Groups did differ significantly in startle magnitude (see Figure 3) with lower startle magnitude exhibited by the $30-\mathrm{mg}$ dose group. However, both the PPI-enhancing effects of $20 \mathrm{mg}$ memantine and the lack thereof with $30 \mathrm{mg}$ memantine were independent of startle magnitude: median split analyses revealed no significant interaction of low $v s$ high startle magnitude and memantine dose effects with either $20 \mathrm{mg}$ $(\mathrm{F}<1)$ or $30 \mathrm{mg}(\mathrm{F}<1)$ doses. Furthermore, startle magnitude was not related to low- $v s$ high-gating group assignment for either dose of memantine, nor did inclusion of low $v s$ high baseline startle magnitude as a grouping factor alter the critical main or interaction effects in these studies. Groups also differed significantly in HA scores (Table 3). However, a subgroup of subjects from the $30-\mathrm{mg}$ dose group $(n=12)$ with mean HA score $(6.0 \quad(\mathrm{SEM}=0.88))$ nearly identical to that of the $20-\mathrm{mg}$ dose group (5.95 $(\mathrm{SEM}=1.25))$ exhibited no significant effect of memantine dose on PPI $(\mathrm{F}<1)$, and no dose $\times$ interval interaction $(\mathrm{F}<1)$. Thus, group differences in HA scores do not appear to account for differential effects of 20 vs $30 \mathrm{mg}$ memantine on PPI.

A narrow dose range of memantine effects on PPI in humans would be consistent with the present animal data for short prepulse intervals. Here, an 'inverted-U' dose effect was detected; the 'low dose' (10 mg/kg) increased PPI compared with vehicle, whereas the 'high dose' $(20 \mathrm{mg} / \mathrm{kg})$ reduced PPI compared with vehicle. Such a pattern suggests interactions among multiple substrates, either among different pharmacological effects of memantine (eg DA agonist as well as NMDA antagonist properties (Seeman et al, 2008)), or multiple brain systems regulating PPI. For example, we could speculate that the ratio of DA agonist:
NMDA antagonist effects of memantine differs at these two doses, such that a predominant NMDA antagonism at the low dose leads to increased PPI, and more prominent DA agonist effects of the high dose opposes these effects of NMDA blockade. It would be less speculative to suggest that the overall effect of systemically administered memantine on PPI will reflect its integrated effects on different brain substrates. Animal studies suggest that different NMDA systems have opposing effects on PPI. For example, PPI is disrupted by infusion of NMDA into the ventral hippocampus (Wan et al, 1996, Zhang et al, 2002, Swerdlow et al, 2001) and by infusion of NMDA antagonists into the basolateral amygdala (Fendt et al, 2000). Thus, a narrow dose range for memantine-induced changes in PPI might reflect its simultaneous action within two or more brain systems with opposing effects on PPI.

It would be reasonable to ask whether different dose effects on PPI might relate to different effects of $20 v s 30 \mathrm{mg}$ of memantine on subjective ratings in this study. Increased 'happy' scores after 20, but not $30 \mathrm{mg}$ memantine, suggests that the lower dose had mild hedonic effects that might correspond to pro-DAergic properties of this drug (Seeman et al, 2008). However, PPI-enhancing effects of pro-DAergic drugs, such as amphetamine, are generally not reported in humans, except perhaps among low-gating subgroups (Swerdlow et al, 2008). Also arguing against a pro-DAergic mechanism for PPI-enhancing effects of memantine is the fact that high novelty-seeking subjects - who are most sensitive to the PPI-enhancing effects of memantine-are also most sensitive to the PPI-reducing effects of DA agonists (Hutchison et al, 1999; Swerdlow et al, 2008). Thus, it would be challenging to propose a parsimonious neurochemical connection between the hedonic and PPIenhancing effects of $20 \mathrm{mg}$ memantine.

The present data also make it hard to explain reduced PPI in schizophrenia, simply on the basis of reduced NMDA neurotransmission. Rather, the present evidence - together with the findings of increased PPI after ketamine and amantadine in normal comparison subjects - suggests that acute systemic blockade of NMDA does not reproduce the loss of sensorimotor gating exhibited by schizophrenia patients. If reduced NMDA neurotransmission contributes to PPI deficits in these patients, such effects might reflect regionally specific changes, or neuroadaptive responses to a chronic hypoglutamatergic state, that are not modeled in normal comparison subjects by an acute drug challenge.

In summary, bioactive doses of the NMDA antagonist, memantine, cause dose- and interval-dependent changes in PPI in rats and normal humans. In rats, $10 \mathrm{mg} / \mathrm{kg}$ memantine increases short-interval PPI, and $20 \mathrm{mg} / \mathrm{kg}$ decreases long-interval PPI. In humans, $20 \mathrm{mg}$ memantine has mild hedonic effects and reduces spontaneous blink rate, and significantly increases long-interval PPI. This latter effect is most evident among individuals with low baseline PPI, or with personality scale scores suggesting high NS, high SSS, or high DIS. At $30 \mathrm{mg}$, memantine causes significant dizziness, but has no effects on PPI at any prepulse interval or in any sample subgroup. The PPIenhancing effects of memantine are generally consistent with reports of other NMDA antagonist effects in humans, but are distinct from the effects of memantine or other NMDA antagonists on PPI in rats. 


\section{ACKNOWLEDGEMENTS}

This study was supported by a Grant no. MH59803. We thank Ms Maria Bongiovanni for her expert assistance in manuscript preparation.

\section{DISCLOSURES/CONFLICT OF INTEREST}

In the past 3 years, NRS has had grant support from Pfizer Pharmaceuticals and Allergan Inc., and is a paid consultant to Sanofi/Aventis. All other authors declare no conflict of interest.

\section{REFERENCES}

Aasen I, Kolli L, Kumari V (2005). Sex effects in prepulse inhibition and facilitation of the acoustic startle response: implications for pharmacological and treatment studies. J Psychopharmacol 19: 39-45.

Abel KM, Allin MP, Hemsley DR, Geyer MA (2003). Low doses of ketamine increases prepulse inhibition in healthy men. Neuropharmacology 44: 729-737.

Areosa SA, Sherriff F, McShane R (2005). Memantine for dementia. Cochrane Database for Systematic Reviews CD 003154.

Bitsios P, Giakoumaki SG, Frangou S (2005). The effects of dopamine agonists on prepulse inhibition in healthy men depend on baseline PPI values. Psychopharmacology 182: 144-152.

Braff D, Stone C, Callaway E, Geyer M, Glick I, Bali L (1978). Prestimulus effects on human startle reflex in normals and schizophrenics. Psychophysiology 15: 339-343.

Braff DL, Geyer MA, Swerdlow NR (2001). Human studies of prepulse inhibition of startle: normal subjects patient groups and pharmacological studies. Psychopharmacology 156: 234-258.

Cadenhead KS, Carasso BS, Swerdlow NR, Geyer MA, Braff DL (1999). Prepulse inhibition and habituation of the startle response are stable neurobiological measures in a normal male population. Biol Psychiatry 45: 360-364.

Castellanos FX, Fine EJ, Kaysen D, Marsh WL, Rapoport JL, Hallett M (1996). Sensorimotor gating in boys with Tourette's syndrome and ADHD: preliminary results. Biol Psychiatry 39: 33-41.

Cloninger CR, Przybeck TR, Svrakic DM (1991). The tridimensional personality questionnaire: US normative data. Psychol Rep 69(3 Part 1): 1047-1057.

Cummings JL (2004). Alzheimer's disease. N Engl J Med 351: 56-67.

Csomor PA, Stadler RR, Feldon J, Yee BK, Geyer MA, Vollenweider FX (2008). Haloperidol differentially modulates prepulse inhibition and P50 suppression in healthy humans stratified for low and high gating levels. Neuropsychopharmacology 33: 497-512.

Duncan EJ, Madonick SH, Parwani A, Angrist B, Rajan R, Chakravorty S, Efferen TR, Szilagyi S, Stephanides M, Chappell PB, Gonzenbach S, Ko GN, Rotrosen JP (2001). Clinical and sensorimotor gating effects of ketamine in normals. Neuropsychopharmacology 25: 72-83.

Earleywine M, Finn PR, Peterson JB, Pihl RO (1992). Factor structure and correlates of the tridimensional personality questionnaire. J Stud Alcohol 53: 233-238.

Eisenberg DTA, Campbell B, Mackillop J, Lum JK, Wilson DS (2007). Season of birth and dopamine receptor gene associations with impulsivity, sensation seeking and reproductive behaviors. PLOS ONE 2: e1216.

Fendt M, Schwienbacher I, Koch M (2000). Amygdaloid N-methyl$\mathrm{D}$-aspartate and gamma-aminobutyric acid(A) receptors regulate sensorimotor gating in a dopamine-dependent way in rats. Neuroscience 8: 55-60.
Frankland PW, Wang Y, Rosner B, Shimizu T, Balleine BW, Dykens EM et al (2004). Sensorimotor gating abnormalities in young males with fragile $\mathrm{X}$ syndrome and Fmr1-knockout mice. Mol Psychiatry 9: 417-425.

Graham FK (1975). The more or less startling effects of weak prestimulation. Psychopsysiology 12: 238-248.

Hart CL, Haney M, Foltin RW, Fischman MW (2002). Effects of the NMDA antagonist memantine on human methamphetamine discrimination. Psychopharmacology (Berl) 164: 376-384.

Hutchison KE, Swift R (1999). Effect of d-amphetamine on prepulse inhibition of the startle reflex in humans. Psychopharmacology 143: 394-400.

Hutchison KE, Wood MD, Swift R (1999). Personality factors moderate subjective and psychophysiological responses to damphetamine in humans. Exp Clin Psychopharm 7: 493-501.

Hoenig K, Hochrein A, Quednow BB, Maier W, Wagner M (2005). Impaired prepulse inhibition of acoustic startle in obsessivecompulsive disorder. Biol Psychiatry 57: 1153-1158.

Ison JR, Hammond GR (1971). Modification of the startle reflex in the rat by changes in auditory and visual environments. J Comp Physiol Psychol 75: 435-452.

Jovanovic T, Szilagyi S, Chakravorty S, Fiallos AM, Lewison BJ, Parwani A, Schwartz MP, Gonzenbach S, Rotrosen JP, Duncan EJ (2004). Menstrual cycle phase effects on prepulse inhibition of acoustic startle. Psychophysiology 41: 401-406.

Karson CN (1983). Spontaneous eye-blink rates and dopaminergic systems. Brain 106(Part 3): 643-653.

Kumar S (2004). Memantine: pharmacological properties of clinical use. Neurol India 52: 307-309.

Kumari V, Gray JA, Geyer MA, ffytche D, Mitterschiffthalaer MT, Vythelingum GN, Williams SCR, Simmons A, Shatma T (2003). Neural correlates of prepulse inhibition in normal in schizophrenic subjects: a functional MRI study. Psychiatry Res Neuroimmag 122: 99-113.

Light GA, Swerdlow NR, Cadenhead KS, Sprock J, Radant A, Braff DL (2007). One year stability of neurophysiological and cognitive endophenotypes of schizophrenia. Proc Am Col Neuropsychopharmacol: 170.

Mansbach RS, Geyer MA (1989). Effects of phencyclidine and phencyclidine biologs on sensorimotor gating in the rat. Neuropsychopharmacology 2: 229-308.

Mansbach RS, Geyer MA (1991). Parametric determinants in prestimulus modification of acoustic startle: interaction with ketamine. Psychopharmacology 105: 162-168.

Mansbach RS, Geyer MA, Braff DL (1988). Dopaminergic stimulation disrupts sensorimotor gating in the rat. Psychopharmacology 94: 507-514.

Martinez ZA, Ellison GD, Geyer MA, Swerdlow NR (1999). Effects of sustained phencyclidine exposure on sensorimotor gating of startle in rats. Neuropsychopharmacology 2: 28-39.

Martinez ZA, Oostwegel J, Geyer MA, Ellison GD, Swerdlow NR (2000). 'Early' and 'late' effects of sustained haloperidol on apomorphine- and phencyclidine-induced sensorimotor gating deficits. Neuropsychopharmacology 23: 517-527.

Ralph RJ, Caine SB (2005). Dopamine D1 and D2 agonist effects on prepulse inhibition and locomotion: comparison of SpragueDawley rats to Swiss-Webster, 129X1/SvJ, C57BL/6J, and DBA/2J mice. J Pharmacol Exp Ther. 312: 733-741.

Seeman P, Caruso C, Lasaga M (2008). Memantine agonist action at dopamine D2High receptors. Synapse 62: 149-153.

Sonkusare SK, Kau CL, Ramarao P (2005). Dementia of Alzheimer's disease and other neurodegenerative disorders - memantine, a new hope. Pharmacol Res 52: 1-17.

Swerdlow NR, Bakshi V, Waikar M, Taaid N, Geyer MA (1998). Seroquel, clozapine and chlorpromazine restore sensorimotor gating in ketamine-treated rats. Psychopharm 140: 75-80.

Swerdlow NR, Benbow CH, Zisook S, Geyer MA, Braff DL (1993). A preliminary assessment of sensorimotor gating in 
patients with obsessive compulsive disorder. Biol Psychiatry 15: 298-301.

Swerdlow NR, Eastvold A, Gerbranda T, Uyan KM, Hartman P, Doan Q, Auerbach P (2000). Effects of caffeine on sensorimotor gating of the startle reflex in normal control subjects: Impact of caffeine intake and withdrawal. Psychopharmacology 151: 368-378.

Swerdlow NR, Hanlon FM, Henning L, Kim YK, Gaudet I, Halim ND (2001). Regulation of sensorimotor gating in rats by hippocampal NMDA: anatomical localization. Brain Res 898: 195-203.

Swerdlow NR, Hartman PL, Auerbach PP (1997). Changes in sensorimotor inhibition across the menstrual cycle: implications for neuropsychiatric disorders. Biol Psychiatry 41: 452-460.

Swerdlow NR, Paulsen J, Braff DL, Butters N, Geyer MA, Swenson MR (1995). Impaired prepulse inhibition of acoustic and tactile startle response in patients with Huntington's disease. J Neurol Neurosurg Psychiatry 58: 192-200.

Swerdlow NR, Platten A, Shoemaker J, Pitcher L, Auerbach P (2001d). Effect of pergolide on sensorimotor gating of the startle reflex in rats. Psychopharmacology 158: 230-240.

Swerdlow NR, Shoemaker JM, Auerbach PP, Pitcher L, Goins J, Platten A (2004). Heritable differences in the dopaminergic regulation of sensorimotor gating: II. Temporal, pharmacologic and generational analyses of apomorphine effects on prepulse inhibition. Psychopharmacology 174: 452-462.

Swerdlow NR, Stephany N, Shoemaker JM, Ross L, Wasserman LC, Talledo J, Auerbach PP (2002). Effects of amantadine and bromocriptine on startle and sensorimotor gating: parametric studies and cross-species comparisons. Psychopharmacology (Berl) 164: 82-92.

Swerdlow NR, Stephany N, Wasserman LC, Talledo J, Shoemaker J, Auerbach PP (2003). Amphetamine effects on prepulse inhibition across-species: replication and parametric extension. Neuropsychopharmacology 28: 640-650.
Swerdlow NR, Talledo J, Sutherland AN, Nagy D, Shoemaker JM (2006). Antipsychotic effects on prepulse inhibition in normal 'low gating' humans and rats. Neuropsychopharmacology 31: 2011-2021.

Swerdlow NR, Weber M, Qu Y, Light GA, Braff DL (2008). Realistic expectations of prepulse inhibition in translational models for schizophrenia research. Psychopharmacology (Berl) 199: 331-388.

Talledo JA, Sutherland Owens AN, Schortinghuis T, Swerdlow NR (2009). Amphetamine effects on startle gating in normal women and female rats. Psychopharmacology (Berl) 16 Jan. [E-pub ahead of print].

van Berckel BN, Oranje B, van Ree JM, Verbaten MN, Kahn RS (1998). The effects of low dose ketamine on sensory gating, neuroendocrine secretion and behavior in healthy human subjects. Psychopharmacology 137: 271-281.

Wan FJ, Caine SB, Swerdlow NR (1996). The ventral subiculum modulation of prepulse inhibition is not mediated via dopamine D2 or nucleus accumbens non-NMDA glutamate receptor activity. Eur J Pharmacol 314: 9-18.

Wilcock G, Mobius HJ, Stoffler A, MMM 500 group (2002). A double-blind, placebo-controlled multicentre study of memantine in mild to moderate vascular dementia (MMM500). Int Clin Pychopharmacol 17: 297-305.

Wiley JL, Harvey SA, Balster RL, Nicholson KL (2003). Affinity and specificity of N-methyl- D-aspartate channel blockers affect their ability to disrupt prepulse inhibition of acoustic startle in rats. Psychopharmacology (Berl) 165: 378-385.

Zhang WN, Bast T, Feldon J (2002). Effects of hippocampal Nmethyl-D-aspartate infusion on locomotor activity and prepulse inhibition: differences between the dorsal and ventral hippocampus. Behav Neurosci 116: 72-84.

Zuckerman M, Bone RN, Neary R, Mangelsdorf D, Brustman B (1974). What is the sensation seeker? Personality trait and experience correlates of the sensation-seeking scales. J Consulting Clin Psychol 39: 308-321. 